\title{
Tumor Lysis like Syndrome Associated with Cytomegalovirus: A Case Report
}

Hasan YETER H $^{1^{*}}$, Mahdi HOUSSEIN ${ }^{1}$ and Meltem Gülhan HALIL ${ }^{2}$

${ }^{1}$ Department Of Internal Medicine, Hacettepe University Medical School, Ankara, Turkey

${ }^{2}$ Department of Geriatrics, Hacettepe University Medical School, Ankara, Turkey

*Corresponding author: Yeter HH, Department Of Internal Medicine, Hacettepe University Medical School, Ankara, Turkey, Tel: 905542397449; E-mail: hasanyeter@hotmail.com

Rec date: May 18, 2015; Acc date: Jul 21, 2015; Pub date: Jul 23, 2015

Copyright: (C) 2015 Yeter $\mathrm{HH}$, et al. This is an open-access article distributed under the terms of the Creative Commons Attribution License, which permits unrestricted use, distribution, and reproduction in any medium, provided the original author and source are credited.

\begin{abstract}
:
Cytomegalovirus (CMV) is generally asymptomatic in immunocompetent patients. The most common clinical syndrome associated with CMV is mononucleosis syndrome characterized by fever, fatigue, sore throat, generalized lymphadenopathy, impaired liver function, and lymphocytosis. İn this case a 51 year-old female patient was considered as having tumor lysis syndrome due to presentation with weight loss, fever and night sweats and high levels of creatinine and uric acid. In this case lymphoproliferative diseases were the first to be investigated, however corresponding test results were negative and the serological tests showed an active CMV infection.
\end{abstract}

Keywords: Cytomegalovirus; Tumor lysis syndrome

\section{Introduction}

CMV, a double strand DNA virus, is a member of herpes virus family and beta-herpesvirus subfamily. Most people are infected with CMV sometime in their lives. People in developing countries are generally infected with CMV quite early in their lives. CMV infection usually occurs in perinatal period and infancy or by sexual contact during adulthood. While congenital infections significantly cause mortality and morbidity, most primary CMV infections in immunocompetent adults are either asymptomatic or causes mononucleosis like syndrome. After the primary infection, virus can cause lifelong latent or persistant infections in a variety of cells and tissues such as monocytes, macrophages, neutrophils, leukocytes, lymphocytes, vascular entothelial cells, kidney epithelial cells, salivary glands [1-5].

Tumor lysis syndrome (TLS) is a manifestation caused by rapid lysis of tumor cells and may lead to fatal metabolic abnormalities. These abnormalities are caused by the leakage of intracellular ions, nucleic acids, proteins and metabolites from intracellular space to extracellular space of tumor cells. Rapid leakage of metabolites can disrupt hemostatis and cause uremia, hyperuricemia, hyperkalemia and hyperphosphatemia. Whereas, hypocalcemia which is a common condition in tumor lysis syndrome can develop secondary to hyperphosphatemia $[6,7]$.

In this case report, an immunocompetent patient with tumor lysis syndrome and acute kidney failure caused by CMV infection was presented.

\section{Case Report}

A 51 year-old female patient, married with children, was admitted to emergency department with general poor health. She had no history of any prior disease except hypertension. Physical examination revealed confusion, dyspnea, decreased urine output, chest pain, and pretibial edema. Her body temperature was 40 degrees celcius, respiration rate was 26 per minute, and blood pressure was 100/55 $\mathrm{mm} / \mathrm{hg}$. Posterio-anterior chest radiograph showed pleural effusion and increased infiltration of right para-cardiac region. ECG did not reveal any finding related with ischemia. Abnormalities were present in liver function tests and kidney function tests at the time of hospitalization (Table 1). Additionally, she had leukocytosis and thrombocytopenia.

\begin{tabular}{|l|l|l|l|l|l|l|}
\hline & Admission & Pre-dialysis & Post-dialysis & $\begin{array}{l}\text { Follow up at } \\
\text { the clinic }\end{array}$ & $\begin{array}{l}\text { Follow up at the } \\
\text { Discharge } \\
\text { outpatient clinic* }\end{array}$ \\
\hline Leukocyte $\left(\times 10^{3} / \mathrm{ul}\right)$ & 63.8 & 53.7 & 51.1 & 7.9 & 9 & 8.6 \\
\hline Thrombocyte $\left(\times 10^{3} / \mathrm{ul}\right)$ & 27 & 20 & 18 & 209 & 239 & 398 \\
\hline ALP(U/L)) & 475 & & & 213 & 210 & 126 \\
\hline GGT(U/L) & 281 & & & 80 & 80 & 80 \\
\hline Creatinine $(\mathrm{mg} / \mathrm{dl})$ & 3.42 & 3.82 & 2.45 & 0.79 & 0.75 & 0.57 \\
\hline Uric acid(mg/dl) & 12.95 & 12.97 & 7.35 & 4.2 & 4.8 & 4.5 \\
\hline CRP(mg/dl) & 25.1 & 24 & 3.49 & 2.37 & & \\
\hline
\end{tabular}


Page 2 of 3

\begin{tabular}{|l|l|l|l|l|l|l|}
\hline Procalsitonine $(\mathrm{ng} / \mathrm{ml})$ & 8.71 & 5.51 & 0.7 & 0.28 & & \\
\hline ESR $(\mathrm{mm} / \mathrm{hr})$ & 15 & 24 & 37 & 30 & 23 & 33 \\
\hline CMV serology & & & 0.09 (negative) & & \\
\hline cmv viral load(copy/ml) & & & 10,571 & 21,271 & & \\
\hline${ }^{*}$ Infectious Diseases Outpatient Clinic & & & \\
\hline
\end{tabular}

Table 1: Depicts the results of liver and kidney function tests.

Patient was considered septic and started tazobactam piperacillin at renal dose. Jugular catheterization and hemodialysis were done due to kidney function abnormalities and anuria. Kidney function abnormalities and electrolytes returned to normal values after dialysis. Hydroxiurea $1 \times 500 \mathrm{mg}$ was started for leukocytosis and allopurinol $300 \mathrm{mg}$ was given.

General condition of the patient returned to normal and her condition was accepted as spontaneous tumor lysis syndrome. Lymphoproliferative diseases were considered for pre-diagnosis due to accompanying leukocytosis.

Her peripheral smear for lymphoproliferative diseases did not show any lymphoblastic cells. Bone marrow aspiration biopsy was reported as 'normo-cellular bone marrow'. AML and ALL tests from peropheral blood came out negative. Thorax and abdominal computed tomography (CT) were performed and reported as 'widespread bilateral axillary, retropectoral, supraclavicular, mediastinal and hilar lymphadenopathies', therefore lymph node excision was planned. However, when the consequent CT scan revealed significant regression in size and number of mediastinal and hilar lymph nodes and slight regression of bilateral axillary lymph nodes; diagnosis of lymphoma was thought to be not likely since she had no corticosteroid treatment or chemotherapy. Patient was also evaluated for autoimmune diseases. However, ANA (anti-nuclear antibody), ANCA (anti-neutrophil cytoplasmic antibody), ENA (extractable nuclear antigen), C3, C4, lymphocyte subsets and immunoglobulin levels were in normal range. Viruses causing myocarditis were considered for diagnosis due to her chest pain at the time of admission. Samples were collected for CMV, EBV, coxsackie virus and parvovirus. Patient's CMV viral load came out as $21271 \mathrm{copy} / \mathrm{ml}$, whereas tests were other viruses were negaive. Patient was considered to have primary CMV disease.

\section{Discussion}

Tumor lysis syndrome is an oncologic emergency that is typically seen in malignancies with high turn over rates such as acute leukemia, high grade lymphoma, germ cell tumors, and small cell lung cancer. Our patient had high uric acid levels, hyperphosphatemia, and hypocalcemia at the time of admission. Hyperkalemia was not present. Therefore, patient was considered to have tumor lysis syndrome. Isolated high uric acid levels are expected in spontaneous TLS due to high turnover rate of tumor cell and reuse of phosphate and potasssium. This type of TLS is seen in patients who didn't take chemotherapy and with malign cells that can use ions secreted to extracellular space. On the other hand, during chemotherapy high phosphorus and potassium levels accompany high uric acid levels due to cell lysis [6,7].
Since our patient did not receive chemotherapy and had only high levels of uric acid, she was thought to have spontaneous TLS. Therefore she was evaluated for hematological malignencies. High leukocyte and LDH levels supported our hypothesis. Bone marrow biopsy was reported as 'normo-cellular bone marrow', $t(9: 22)$ mutation was negative, and AML and ALL panels in cytogenetic study were also both negative. CT scan revealed significant regression in lymphadenopathies.

When the patient was evaluated for other possible malignancies, all tumor markers came out negative.

Patients with fever and widespread lymphadenopathies should be evaluated for autoimmune diseases. Autoimmune markers of our patient were in normal range. In addition, she did not have any skin findings, photosensitivitiy, joint problem, dryness of mouth and eyes, reynaud phenomenon or similar findings.

After ruling our autoimmune and malignant diseases, EBV and CMV infections were considered and finally, a high viral load of CMV was detected in the patient.

\section{Conclusion}

Most people face CMV infection sometime in their lives. CMV infections are mostly asymptomatic; however its clinical course can vary from mild symptoms to fatal conditions.

Signs and symptoms of CMV infection can vary according to age, route of transmission, and immune status of the patient. In immunocompetent patients, CMV infection is asymptomatic and stays subclinical. It may cause fever, cold feeling, myagia, hepatitis, leukocytosis, atypical lymphocytes, hepatomegaly, splenomegaly, pharyngitis and cervical lymphadenopathy. Fever, lymphadenopathy and leukocytosis were competent with high viral load of CMV [8].

In conclusion, it should be emphasized that in patients with widespread lymphadenopathy and leukocytosis, CMV infection should be considered. Additionally, this condition might also be seen in other viral infections which lymphadenopathies accompany.

In the comprehensive literature research, no case, presenting CMV infection causing tumor lysis like syndrome was found.

\section{References}

1. Cohen JI, Corey GR (1985) Cytomegalovirus infection in the normal host. Medicine (Baltimore) 64: 100-114.

2. Horwitz CA, Henle W, Henle G, Snover D, Rudnick H, et al. (1986) Clinical and laboratory evaluation of cytomegalovirus-induced mononucleosis in previously healthy individuals. Report of 82 cases. Medicine (Baltimore) 65: 124-134. 
Citation: YETER HH, HOUSSEIN M, HALIL MG (2015) Tumor Lysis like Syndrome Associated with Cytomegalovirus: A Case Report . J Cytol Histol 6: 350. doi:10.4172/2157-7099.1000350

Page 3 of 3

3. Gandhi MK, Khanna R (2004) Human cytomegalovirus: clinical aspects, immune regulation, and emerging treatments. Lancet Infect Dis 4 : 725-738.

4. Söderberg-Nauclér C, Fish KN, Nelson JA (1997) Reactivation of latent human cytomegalovirus by allogeneic stimulation of blood cells from healthy donors. Cell 91: 119-126.

5. Ross SA, Arora N, Novak Z, Fowler KB, Britt WJ, et al. (2010) Cytomegalovirus reinfections in healthy seroimmune women. J Infect Dis 201: 386-389.
6. Hande KR, Garrow GC (1993) Acute tumor lysis syndrome in patients with high-grade non-Hodgkin's lymphoma. Am J Med 94: 133-139.

7. van den Berg H, Reintsema AM (2004) Renal tubular damage in rasburicase: risks of alkalinisation. Ann Oncol 15: 175-176.

8. Isik YB, Karakis YT, Akin M (2006)Sitomegalovirus enfeksiyonlu olgular. 50. milli pediatri kongresi. 